\title{
CONGENITAL SPCA DEFICIENCY: A HITHERTO UNRECOGNIZED COAGULATION DEFECT WITH HEMORRHAGE RECTIFIED BY SERUM AND SERUM FRACTIONS ${ }^{1}$
}

\author{
By B. ALEXANDER, R. GOLDSTEIN, G. LANDWEHR, AND C. D. COOK with \\ THE TECHNICAL ASSISTANCE OF EUNICE ADDELSON AND CLAIRE WILSON \\ (From the Yamins Research Laboratory, Beth Israel Hospital; from the Children's Medical \\ Center, and from the Departments of Medicine and Pediatrics, Harvard Medical \\ School, Boston, Mass.)
}

(Submitted for publication January 17, 1951 ; accepted, March 26, 1951)

\section{INTRODUCTION}

The importance of non-prothrombin plasma and serum constituents in the physiological conversion of prothrombin to thrombin has been recognized only recently. A hemorrhagic disorder, called "parahemophilia" (Owren's disease), is associated with an elevated prothrombin time attributable to deficiency of a plasma component termed "Factor V" $(1,2)$. Inadequacy of plasma Ac-globulin, required for rapid evolution of thrombin, has been described by Sykes and associates (3) in experimentally induced liver poisoning, and Alexander and Goldstein have reported on Labile Factor (Quick) deficiency in severe hepatic disease in man (4). Although conclusive evidence is lacking, most investigators agree that Factor V, Acglobulin, and Labile Factor are identical. Subnormal concentrations result in retarded prothrombin conversion (elevated one-stage prothrombin time), in poor yield of thrombin by the two-stage prothrombin method, and in hemorrhagic phenomena despite the fact that the prothrombin level may actually be normal.

The clinical and laboratory investigation of a unique case herein reported provides substantial evidence that an additional constituent besides that (or those) described above is involved in prothrombin conversion, and that its lack may underlie a hemorrhagic diathesis, hitherto unrecognized, which simulates hypoprothrombinemia. Deficiency of Ac-globulin, Labile Factor, or Factor $\mathrm{V}$ were excluded as the basis for the clotting abnormality. The evidence warrants the conclusion that the defect consisted in derangement of the early activation of prothrombin due to congenital inadequacy of the precursor of the serum prothrombin conversion

1 Aided by grants from the Commonwealth Fund and The United States Public Health Service. accelerator (spca) described in earlier reports (5-8).

\section{CASE REPORT 2}

R (No. 309157), a four year old white girl of Scotch, Irish, French and Dutch extraction, was admitted to the Children's Medical Center, Boston, on June 13, 1950, with bloody stools and hematemesis of three days' and six hours' duration, respectively. The family history was contributory only in the fact that the mother stated that she and her brother bruised easily and that the maternal grandfather died of intestinal bleeding following trauma.

The patient, an only child, was noted to have prolonged bleeding from the umbilical cord at birth. On the eighth and tenth days, she passed gross blood per rectum, which continued until the age of five weeks when she was first admitted to the Children's Medical Center. At that time her blood count, platelet count, and bleeding and clotting times were normal. The prothrombin was not determined. Although the barium enema was negative, an exploratory laparotomy was performed because of continued melena. No cause for the intestinal bleeding could be found, the abdominal organs appeared normal, and the appendix was removed. No undue hemorrhage was encountered, and convalescence was uneventful except for mild melena which continued for several months.

The patient's intervening history was perfectly normal save for easy bruising and occasional spontaneous epistaxis. Three weeks prior to her second admission she began to experience urinary urgency, frequency, and burning, unassociated with other symptoms. Five days prior to admission, she fell and sustained some bruises. The next day she passed four tarry stools, pallor was noted, and the patient became progressively listless. On the day of admission she began to bleed from the nose, vomited "coffee-ground" material on three occasions, and complained of crampy abdominal pain.

Physical examination revealed a fairly well developed, thin, very pale, quiet child who appearead acutely ill. T. $99^{\circ}$ F.; pulse 130 ; respirations 30 ; B. P. $100 / 50$. The skin showed a few small ecchymoses over the left leg, abdomen and forehead, but no petechiae. The nares con-

\footnotetext{
${ }^{2}$ From the records of the Children's Medical Center.
} 
tained a moderate amount of dry, clotted blood but no bleeding points were seen. Except for blood in the posterior nasopharynx, the throat was negative. The lungs were clear. The heart was slightly enlarged to the left, rate rapid, rhythm regular; a grade 2 systolic murmur was audible over the apex and left sternal border. The abdomen was completely negative; liver, kidneys and spleen were not palpable. There was no adenopathy. Rectal examination as well as the remainder of the physical examination was negative.

Clinical laboratory data: $\mathrm{Rbc}, 1.94 ; \mathrm{Hgb}, 6.0 \mathrm{gm}$. ; Wbc, 14,800 with normal differential; platelets appeared abundant on the stained smear; platelet count 412,000 ; reticulocytes, $7.5 \%$; sedimentation rate, $4 \mathrm{~mm}$. per hour; hematocrit, $17 \%$ packed cells. Six urines were completely negative; stools were repeatedly guaiac positive during the first three days but were negative thereafter. Hinton was negative. Liver function tests were within normal limits.

On admission, the bleeding time (Duke) was 12.5 minutes; the clotting time was six minutes; clot retraction was normal. The prothrombin time was 72 seconds (control 17).

$\mathrm{X}$-ray examination of the abdomen, including barium enema, revealed normal findings.

Clinical course: A fresh whole blood transfusion of $500 \mathrm{ml}$. was slowly given, beginning at 2:15 P.M., June 13 and ending 1:20 A.M., June 14. The patient's clinical condition improved markedly. In addition, she received $4.8 \mathrm{mgm}$. Hykinone both subcutaneously and intravenously. At 7:00 A.M. on June 14 the prothrombin time was 55 seconds (control 16). The $\mathrm{Rbc}$ and $\mathrm{Hgb}$ had increased to 4.3 million and $14.8 \mathrm{gm}$., respectively. The bleeding time was six minutes.

On June 14, the patient was placed on Synkavite (menadione) $10 \mathrm{mgm}$. p.o.q. six hours and Hykinone $10 \mathrm{mgm}$. s.c.q. six hours. Another transfusion of $250 \mathrm{ml}$. of fresh whole blood was administered, beginning at 3:00 P.M. and ending 6:45 P.M. On June 16 the prothrombin time was 64 seconds (control 15).

After considerable improvement, with no recurrence of hematemesis or melena, the patient was discharged on the eighth day. She was $\operatorname{seen}^{3}$ again four months later at which time her clotting defect was found relatively unchanged; her prothrombin time was 62 seconds, her coagulation time (Lee-White, $37^{\circ} \mathrm{C}$ ), 17 minutes (normal: 4-12 minutes.). The investigation of the coagulation defect is recorded below.

\section{METHOD}

Prothrombin was determined by both the one- and twostage methods. In the former, two procedures were employed: the prothrombin time was observed on whole oxalated plasma ( 1 part $0.1 \mathrm{M}$ sodium oxalate to 9 parts venous blood), and on whole plasma diluted with pooled oxalated normal plasma rendered prothrombin free by adsorption with $\mathrm{BaSO}_{4}$ (hereafter referred to as $\mathrm{BaSO}_{4}$ plasma), according to techniques previously described

\footnotetext{
${ }^{3}$ At the Yamins Research Laboratory.
}

(9). In some experiments, the patient's plasma was mixed with normal plasma unadsorbed with $\mathrm{BaSO}_{4}$. Commercial rabbit brain thromboplastin (Difco) was used throughout except where indicated otherwise.

In the two-stage procedure, also, two methods were used: the orthodox technique (10), and the modification of Ware and Seegers (11) in which optimal amounts of Ac-globulin are provided by bovine $\mathrm{BaCO}_{3}$ adsorbed serum ( 1 to 150 dilution). Discrepancies between the results reflect inadequacy of Ac-globulin in the system not containing the bovine serum. Beef lung provided the source of thromboplastin, and Armour Fraction I provided the fibrinogen.

Plasma Labile Factor (L.F.) was measured by the ability of the plasma to rectify the retarded prothrombin conversion of aged normal oxalated pooled plasma in which this clotting component had deteriorated $(12,13)$.

The serum prothrombin conversion accelerator (spca) was determined by a method previously described (5). Serum devoid of spca was prepared by adsorption with $\mathrm{BaSO}_{4}$ (100 mgm. per ml.) for ten minutes at room temperature.

Preparations of prothrombin were obtained from plasma by adsorption with $\mathrm{BaSO}_{4}$ and elution with $5 \%$ solutions of sodium citrate in physiological saline, as described in earlier reports $(14,8)$. Purified spca was similarly prepared from serum according to published methods (8).

\section{RESULTS}

One-and two-stage plasma prothrombin values: The prothrombin time of the patient's whole plasma was repeatedly found elevated to approximately 70 seconds consistent with a prothrombic activity of about $3 \%$ of normal (Table I). This was not referable to prothrombin deficiency, how-

TABLE I

Patient's plasma prothrombic activity

\begin{tabular}{l|c|c|c|c}
\hline & \multicolumn{4}{|c}{ Prothrombic activity } \\
\cline { 2 - 5 } $\begin{array}{c}\text { Date of } \\
\text { determination }\end{array}$ & \multicolumn{2}{|c|}{ One-stage } & \multicolumn{2}{c}{ Two-stage } \\
\cline { 2 - 5 } & Proth. time & Proth. & $\begin{array}{c}\text { Without } \\
\text { Ac-glob. } \\
\text { supplement }\end{array}$ & $\begin{array}{c}\text { With } \\
\text { Ac-glob. } \\
\text { supplement }\end{array}$ \\
\cline { 2 - 5 } & sec. & per cent & units per ml. & units per ml. \\
$6 / 20 / 50$ & 72 & 3 & 170 & 214 \\
$6 / 26 / 50$ & 69 & 3 & 170 & 206 \\
$9 / 29 / 50^{*}$ & 77 & 2 & 184 & 200 \\
$6 / 27 / 50$ & 75 & 2 & 200 & 225 \\
$11 / 2 / 50$ & 62 & 4 & 200 \\
\hline
\end{tabular}

* Plasma of $6 / 26 / 50 \mathrm{kept}$ in frozen state at $-10^{\circ} \mathrm{C}$, thawed and tested on $9 / 29 / 50$.

† Ac-globulin supplement consists of $\mathrm{BaCO}_{3}$ bovine serum.

In our laboratory the prothrombic activity of normal plasma is: one-stage, $80-120 \%$; two-stage, $160-220$ units per $\mathrm{ml}$. 
TABLE II

Prothrombic activity of patient's plasma in combination with normal plasma

\begin{tabular}{|c|c|c|c|c|}
\hline \multicolumn{4}{|c|}{ Plaøma mixture (parts) } & \multirow{2}{*}{$\underset{(\text { sec.) }}{\text { Proth. time" }}$} \\
\hline $\begin{array}{c}\text { Norm. } \\
\text { plas. }\end{array}$ & $\begin{array}{c}\text { Norm. } \\
\text { BaSO; } \\
\text { plas. }\end{array}$ & Pt.'s plas. & $\begin{array}{c}\text { Pt.'s BaSO, } \\
\text { plas. }\end{array}$ & \\
\hline $\begin{array}{l}1 \\
-\end{array}$ & $\frac{9}{9}$ & $\frac{-}{1}$ & $\frac{9}{-}$ & $\begin{array}{c}34 \\
32 \\
120+ \\
100\end{array}$ \\
\hline $\begin{array}{l}1 \\
1\end{array}$ & 9 & - & $\overline{9}$ & $\begin{array}{l}34 \\
38\end{array}$ \\
\hline $\begin{array}{l}1 \\
1 \\
1 \\
1 \\
1 \\
1 \\
-\end{array}$ & $\begin{array}{l}- \\
\overline{9} \\
4 \\
-\end{array}$ & $\begin{array}{l}1 \\
4 \\
9 \\
- \\
-\end{array}$ & $\bar{z}$ & $\begin{array}{l}19 \\
23 \\
26 \\
31 \\
23 \\
17 \\
72\end{array}$ \\
\hline
\end{tabular}

* Prothrombin time observed on $0.1 \mathrm{ml}$. plasma mixture added to $0.1 \mathrm{ml}$. thromboplastin, followed by the addition of $0.1 \mathrm{ml}$. of $0.025 \mathrm{M} \mathrm{CaCl}$. This obtains also for Tables III, IV, VI, VII, VIII.

ever, since by the two-stage method the prothrombin level was consistently within normal limits.

\section{Exclusion of disturbance in thrombin-fibrinogen interaction, antithromboplastin, or anticoagulant}

The elevated prothrombin time could be due either to retarded evolution of thrombin or to some disturbance in the thrombin-fibrinogen interaction. The latter was readily excluded. First, minute amounts of thrombin (Parke-Davis Topical Thrombin) clotted the patient's plasma as rapidly as normal plasma. Second, the prothrombin times of mixtures of normal plasma with the patient's plasma, whole or deprothrombinated by $\mathrm{BaSO}_{4}$ were no greater than those obtained on similar mixtures of normal plasma with normal $\mathrm{BaSO}_{4}$ plasma (Table II). Thus, the clotting defect could not be related to abnormalities in the patient's fibrinogen or antithrombin, to antithromboplastin, or, for that matter, to the presence of any other anticoagulant.

It was obviously necessary to exclude the possibility that the patient's prothrombin might have been resistant to rabbit brain thromboplastin (used in the one-stage method) in contrast to bovine lung thromboplastin (in the two-stage procedure). This hypothesis became untenable when it was found that the prothrombin time was still far above normal when bovine lung thromboplastin was substituted for rabbit brain (Table III). Similar results were also obtained with human brain thromboplastin (acetone dehydrated). Curiously, whereas human thromboplastin was more effective than bovine thromboplastin on normal plasma, it was less effective on the patient's plasma. The explanation for this is obscure.

Exclusion of Ac-globulin deficiency: The question arose as to whether the retarded thrombin evolution was due to inadequacy of any of the known prothrombin-conversion factors. Deficiency of Ac-globulin was easily excluded: twostage plasma prothrombin determinations by the orthodox procedure, in which supplements of Acglobulin are not provided, gave values almost as good as those obtained with added Ac-globulin (Table I, Figure 1). The slightly lower values are not unusual in our experience with hundreds of measurements on normal plasma, and are in accordance with the finding of Murphy and Seegers that normally the concentration of Acglobulin in man is critically low (15). Also noteworthy is the normal activation rate of the prothrombin within the interval observed (Figure 1). This was found repeatedly.

Exclusion of labile factor deficiency: L. F. concentration was also relatively normal. The restorative activity of the patient's plasma, whole or treated with $\mathrm{BaSO}_{4}$, on the retarded prothrombin conversion of aged plasma, was approximately $70 \%$ of normal (Figure 2), a level not infrequently observed in patients with active or recent bleeding. This concentration is certainly sufficient to assure a normal prothrombin time if other clotting constituents are normal $(16,12)$. That the coagu-

\section{TABLE III}

Prothrombic activity of patient's plasma with thromboplastin ( $T$ pl.) from different species

\begin{tabular}{|c|c|c|c|}
\hline & \multicolumn{3}{|c|}{ Prothrombin time (sec.) } \\
\hline & $\underset{\substack{\text { Humain } \\
\text { Tpl. }}}{\text { Tuman }}$ & $\begin{array}{c}\text { Rabbit } \\
\text { brain } \\
\text { Tpl. }\end{array}$ & $\begin{array}{c}\text { Bovine } \\
\text { lung } \\
\text { Tpl. }\end{array}$ \\
\hline $\begin{array}{l}\text { Norm. plas. } \\
\text { Norm. plas. (1) plus norm. } \\
\text { BaSO, plas. (9) } \\
\text { Pt.'s plas. } \\
\text { Pt.'s plas. (1) plus norm. BaSO } \\
\text { plas. (2) }\end{array}$ & $\begin{array}{r}17 \\
33 \\
155 \\
175\end{array}$ & $\begin{array}{l}19 \\
29 \\
77 \\
77\end{array}$ & $\begin{array}{l}25 \\
53 \\
56 \\
62\end{array}$ \\
\hline
\end{tabular}




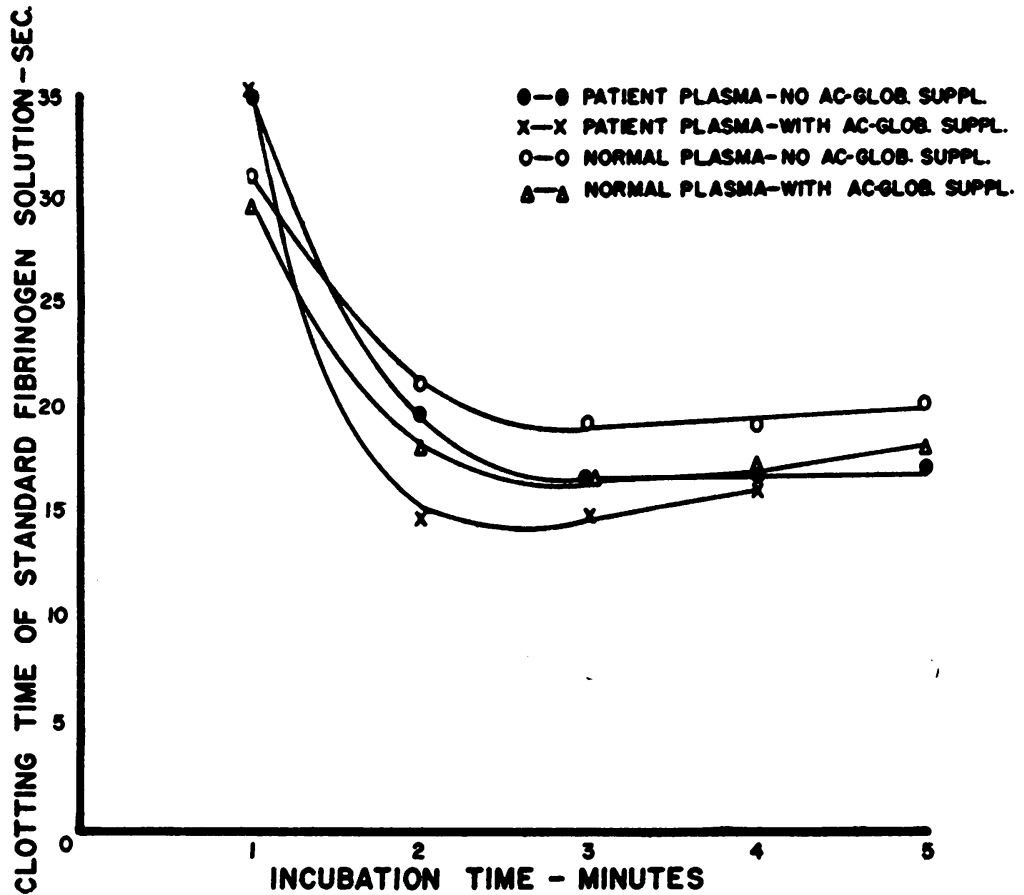

Fig. 1. Two-Stage Prothrombin Conversion of Pathological Compared with Normal Plasma

Ac-globulin supplement consists of bovine $\mathrm{BaCO}_{3}$ adsorbed serum (11). Prothrombin activation performed on a 1 to 40 dilution of test plasma with saline or with a 1 to 150 bovine serum-saline mixture.

lation defect could not be attributed to L. F. deficiency is established by the observation that diluting the patient's plasma with $\mathrm{BaSO}_{4}$ normal plasma, which contains a full complement of L. F. $(16,17)$ failed to rectify the abnormality (Table II). Also, diluting normal plasma with the patient's $\mathrm{BaSO}_{4}$ plasma gave essentially the same prothrombin times as were obtained on normal plasma similarly diluted with normal $\mathrm{BaSO}_{4}$ plasma (Table II). It is, therefore, concluded that the clotting defect was not related to deficiency of Ac-globulin, of L. F., or of any entity contained in $\mathrm{BaSO}_{4}$ adsorbed normal plasma.

Exclusion of Factor $V$ deficiency: Although it is likely that Ac-globulin and L. F. are identical with Factor V, inadequacy of the latter had to be ruled out by methods employed by Owren in his case of parahemophilia $(1,2)$. In his subject, the elevated prothrombin time could be rectified by admixture of deprothrombinated Seitz-filtered normal plasma with the pathological plasma. Accordingly, $35 \mathrm{ml}$. of normal oxalated plasma were passed through a Seitz filter. The first $5 \mathrm{ml}$. were discarded, and the remainder was refiltered through the same pad. The filtrate was prothrombin-free but contained L. F. and Ac-globulin activity. A mixture of 1 part of pathological plasma with 2 parts of normal Seitz-filtered plasma gave a prothrombin time of 88 seconds; a mixture of 1 and

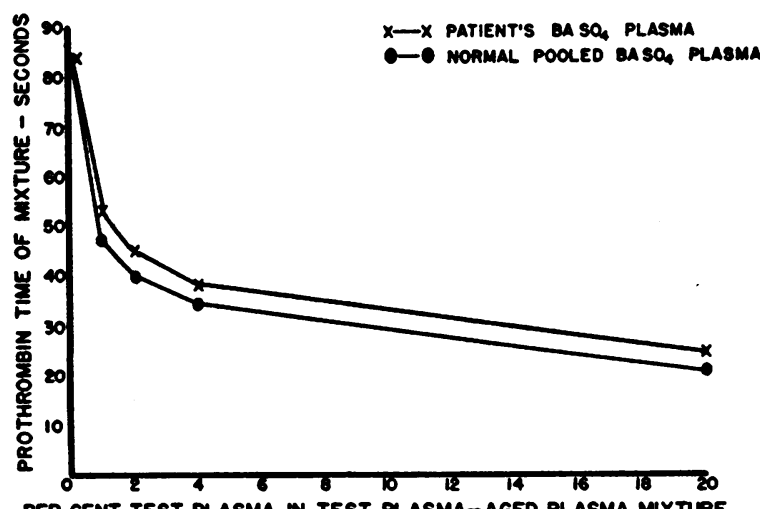

PER CENT TEST PLASMA IN TEST PLASMA-AGED PLASMA MIXTURE

Fig. 2. Labile Factor of Pathological Compared with Normal Plasma

Test material added in various concentrations to normal pooled oxalated plasma aged for five weeks at $45^{\circ} \mathrm{C}$. 
TABLE IV

Activity of prothrombin fraction separated from patient's plasma

Prothrombin fraction dissolved in $0.14 \mathrm{M}$ sodium citrate and $0.15 \mathrm{M} \mathrm{NaCl}$ equivalent in volume to the plasma from which it was derived. The solution contained 184 units of prothrombin per $\mathrm{ml}$. compared with 214 units per $\mathrm{ml}$. in the parent plasma.

\begin{tabular}{c|c|c|c|c}
\hline \hline \multicolumn{3}{c|}{ Mixture (parts) } & \multirow{2}{*}{$\begin{array}{c}\text { Proth. time } \\
\text { (sec.) }\end{array}$} \\
\hline Pt.'s plas. & Pt.'s proth. & Norm. plas. & $\begin{array}{c}\text { BaSO, } \\
\text { norm. plas. }\end{array}$ & \\
\hline 1 & - & - & - & 72 \\
1 & - & - & 9 & 93 \\
- & 1 & - & 4 & $85^{*}$ \\
1 & 1 & - & 18 & 98 \\
- & - & 1 & 19 & 47 \\
\hline
\end{tabular}

* Subsequent determinations gave progressively increasing prothrombin times, indicating rapid deterioration of the prothrombic activity. This phenomenon was observed repeatedly.

9, respectively, failed to clot in six minutes. On the basis of these and other observations (see below), parahemophilia was excluded.

\section{Possibility of qualitative defect in patient's prothrombin}

Conceivably the patient's prothrombin might have been inherently defective, and thus in its early activation only slowly susceptible to the action of thromboplastin and calcium. This might escape detection in the two-stage method where, although thrombin evolution takes place, it is not discernible until after a longer interval (minutes) of interaction between the coagulation components than in the one-stage system (seconds). To test this possibility, the patient's prothrombin was separated and purified. The prothrombin, which was thus obtained in full yield, behaved like that in the whole plasma : it was normal when measured in the two-stage system but when it was added to $\mathrm{BaSO}_{4}$ normal plasma its one-stage conversion was still retarded (Table IV). The possibility still remained, therefore, that the prothrombin molecule itself was abnormal. Clearly, this question can be conclusively answered only by testing the prothrombin in an ideal diluent consisting of hypoprothrombinemic plasma assuredly containing all the accessory prothrombin factors.

Patient's prothrombin consumption: Although two-stage prothrombin conversion was normal, it was of interest to see whether the retarded onestage thrombin formation was associated with decreased prothrombin consumption during the course of spontaneous coagulation. Accordingly, the following experiments were performed: venous blood, drawn with a siliconized syringe and needle, was allowed to clot in clean non-siliconized dry test tubes. At specific intervals after the blood was withdrawn, oxalate was added, the mixture was stirred with a glass rod, and the tubes were centrifuged. Residual prothrombin in the sera was determined by the modified two-stage method. Contrary to what was expected, prothrombin consumption was found perfectly normal (Figure 3 ). This indicates that if prothrombin conversion was retarded, it was so only in an early phase of the clotting process, perhaps within that interval represented by the one-stage prothrombin time where initial thrombin formation is detected. Apparently, as "clotting" proceeded, the velocity of thrombin elaboration increased and soon became normal. This interpretation is consistent with the normal plasma prothrombin values obtained by the twostage method, where normal activation and maximal yield of thrombin was evident within a few minutes after thromboplastin and calcium were added to the system (Figure 1). Under the conditions of the two-stage procedure, a disturbance in the earliest phase of prothrombin activation could escape detection.

Spca mechanism in the pathological blood: It has previously been shown that spca evolves in re-

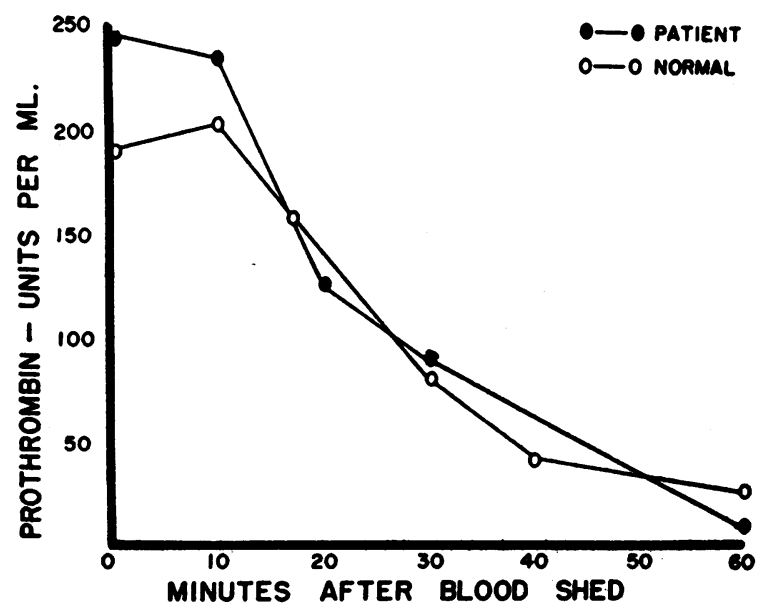

Fig. 3. Prothrombin Consumption during Spontaneous Coagulation 
TABLE $V$

Spca in patient's serum

\begin{tabular}{c|c|c|c|c}
\hline \hline \multirow{2}{*}{ Date } & \multicolumn{4}{|c}{ Spca (Units per ml. of serum)* } \\
\cline { 2 - 4 } & $10^{\prime}$ & $20^{\prime}$ & $30^{\prime}$ & $60^{\prime}$ \\
\hline $6 / 20$ & - & - & 15 & $0(0) \dagger$ \\
$6 / 26$ & - & - & $\frac{1}{2}$ & 2 \\
$6 / 27$ & - & - & 2 \\
$11 / 2$ & 11 & 7 & 0 & 8 \\
\hline
\end{tabular}

Serum oxalated and separated at indicated interval after blood was shed.

* Normal serum contains 14-40 units of spca per ml.

† Value in parentheses obtained on serum from an aliquot of blood $(4.5 \mathrm{ml}$.) placed in tube containing thromboplastin $(0.5 \mathrm{ml}$.) prepared as for prothrombin determination. The effect on the clotting time was not observed in this instance, but on another occasion $0.2 \mathrm{ml}$. of. thromboplastin added to $2.0 \mathrm{ml}$. of the patient's blood lowered the clotting time from 17 to $2 \frac{1}{3}$ minutes. Under these conditions normal blood would have clotted almost instantaneously.

lation to the amount or velocity of prothrombin conversion $(6,7)$. This substance, distinct from Ac-globulin, is considered by us to be the "autocatalytic" accelerator of thrombin formation (8). Arising from an as yet unidentified precursor in plasma, it apparently potentiates the action of thromboplastin (8). Both spca and its progenitor are adsorbable by $\mathrm{BaSO}_{4}(5,7,8,14)$.

In view of the role of spca in prothrombin conversion, it was of interest to study the elaboration of spca during coagulation of the patient's blood. The spca activity of her serum was generally abnormally low despite normal prothrombin consumption (Table V). It was aiso noteworthy that accelerating the clotting of her freshly shed blood with thromboplastin supplements failed to increase the spca, in contrast to what is obtained on normal blood (6). However, on one occasion, 30 minutes after the blood had been shed, spca activity appeared normal, but within the next 30 minutes it had decreased markedly. It was, therefore, possible that the patient's plasma may have exerted a destructive action on whatever spca was elaborated. This was excluded by experiments in which purified spca, separated from normal serum, was incubated at $37^{\circ} \mathrm{C}$ with the pathological plasma. No deterioration occurred in three hours.

Effect of storage on patient's plasma: Plasma

TABLE VI

Effect of normal serum and purified spca on patient's prothrombic activity (one stage)

\begin{tabular}{|c|c|c|c|c|c|c|c|c|c|}
\hline \multicolumn{9}{|c|}{ Mixture (parts) } & \multirow{2}{*}{$\begin{array}{l}\text { Proth. time } \\
(\text { sec.) }\end{array}$} \\
\hline Pt.'s plas. & Pt.'s ser.* & Norm. plas. & Norm. ser. $\dagger$ & $\begin{array}{c}\text { Norm. } \\
\text { BaSO; } \\
\text { ser. }\end{array}$ & $\begin{array}{l}\text { Pt.'s proth. } \\
\text { prep.‡ }\end{array}$ & Spca prep. 8 & Saline & $\begin{array}{c}\text { Norm. } \\
\text { BasO، } \\
\text { plas. }\end{array}$ & \\
\hline $\begin{array}{l}1 \\
1 \\
1 \\
1 \\
1 \\
\end{array}$ & $\frac{-}{\frac{-}{1}}$ & $\frac{-}{\frac{1}{1}}$ & $\frac{-}{\frac{1}{1}}$ & $\begin{array}{l}z \\
z \\
z\end{array}$ & $\begin{array}{l}- \\
z \\
z\end{array}$ & $\begin{array}{l}z \\
z \\
z\end{array}$ & $\begin{array}{l}z \\
z \\
z\end{array}$ & $\begin{array}{l}\frac{9}{-} \\
-\end{array}$ & $\begin{array}{l}72 \\
93 \\
19 \\
15 \\
63 \\
13\end{array}$ \\
\hline$\frac{1}{\frac{1}{1}}$ & $\begin{array}{l}- \\
\frac{-}{1} \\
1\end{array}$ & $\begin{array}{l}- \\
\frac{1}{1} \\
\frac{1}{1}\end{array}$ & $\frac{\overline{1}}{\frac{1}{-}}$ & $\begin{array}{l}- \\
z \\
z\end{array}$ & $\begin{array}{l}z \\
z \\
-\end{array}$ & $\begin{array}{l}- \\
z \\
-\end{array}$ & $\frac{\frac{1}{1}}{-}$ & $\begin{array}{l}18 \\
18 \\
18 \\
18 \\
18 \\
18 \\
18\end{array}$ & $\begin{array}{l}180+ \\
28 \\
47 \\
23 \\
95-130 \\
44\end{array}$ \\
\hline 1 & - & $\overline{1}$ & - & 二 & 二 & $\begin{array}{l}1 \\
1\end{array}$ & 二 & $\begin{array}{l}18 \\
18\end{array}$ & $\begin{array}{l}31 \\
28\end{array}$ \\
\hline E & E & $\bar{z}$ & $\frac{1}{-}$ & $\frac{-}{1}$ & $\begin{array}{l}1 \\
1 \\
1 \\
1\end{array}$ & $\frac{-}{1}$ & E & $\begin{array}{r}4 \\
18 \\
18 \\
18\end{array}$ & $\begin{array}{l}85 \\
32 \\
86-130 \\
24\end{array}$ \\
\hline $\begin{array}{l}1 \\
1\end{array}$ & - & - & - & - & - & $\overline{1}$ & - & 1 & $\begin{array}{l}93 \\
14\end{array}$ \\
\hline
\end{tabular}

* Obtained 60 minutes after blood withdrawn. Contained 2 units prothrombin per ml. (see data of 6/20-Table V).

$\dagger$ Obtained 60 minutes after blood withdrawn. Contained 6 units prothrombin per ml.

Same preparation as described in Table IV. Obtained from patient's plasma used in this experiment.

Solution containing $1 \mathrm{mgm}$. protein, 38 units spca, per $\mathrm{ml}$. 
prothrombic activity, as measured by the orthodox one-stage method, decreases during storage because of deterioration of L. F. $(12,14,18)$. When, however, determinations are made by the modified procedure in which the aged plasma is diluted with fresh $\mathrm{BaSO}_{4}$ plasma, the stored plasma shows increased prothrombic activity. Such "hyperactivity" also develops in aging prothrombin fractions obtained by $\mathrm{BaSO}_{4}$ adsorption, and elution with citrate (14). This is attributable to evolution of a prothrombin conversion accelerator, which because of its resemblance to spca with regard to activity, stability and adsorbability by $\mathrm{BaSO}_{4}$, has been identified with spca.

This phenomenon was not demonstrable in the pathological plasma : during storage of the oxalated plasma in glass at refrigerator temperature for 25 days, no significant change in prothrombic activity was observed.

Effect of spca on the clotting defect: All of these findings suggested a derangement in the spca mechanism. Experiments were therefore performed to ascertain whether normal serum rich in spca could affect prothrombin conversion in the patient's plasma. When normal serum was mixed with the pathological plasma, the prothrombin time was markedly decreased (Table VI). In contrast, the patient's serum was relatively inert on both her own as well as on normal plasma. Normal serum also induced more rapid thrombin evolution from a prothrombin preparation derived from the abnormal plasma, and the same results were obtained when purified spca fractions were substituted for normal serum. Furthermore, re-

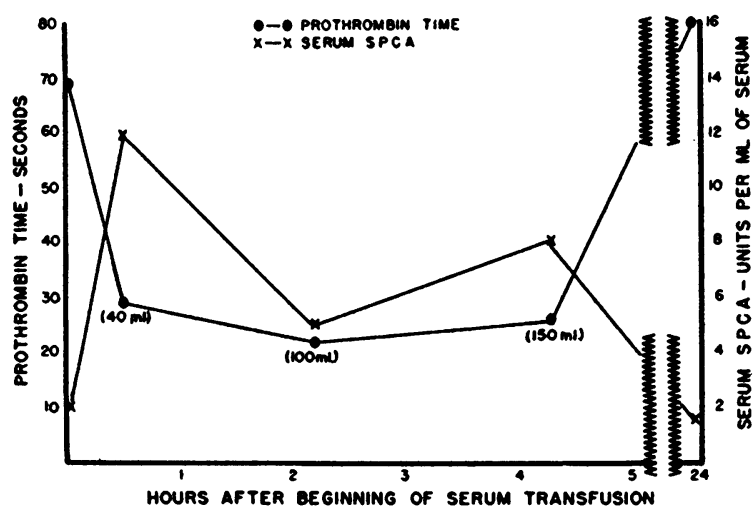

Fig. 4. Effect of Serum Transfusion on Patient's Prothrombin Time and Spca moval of spca from normal serum by $\mathrm{BaSO}_{4}$ adsorption rendered it inert. The clot-promoting effect can therefore be attributed to spca rather than to another serum component.

Effect of serum in vivo: Whether or not a defective spca mechanism was the fundamental disturbance, the in vitro effect of normal serum suggested its use as a therapeutic agent. Accordingly, five days after discharge the patient was readmitted to the Children's Medical Center to receive a slow infusion of $150 \mathrm{ml}$. of 24 hour old normal serum. The prothrombin time decreased markedly, and remained lowered for several hours, but gradually increased to its previous level within 24 hours (Figure 4). Concomitant with the rise in onestage prothrombic activity, the patient's serum spca increased, only to drop rapidly as the beneficial effect of the serum wore off. The two-stage prothrombin values were unchanged.

Clot-promoting effect of plasma compared with serum: It is not clear whether a transfusion of normal blood or plasma would have had the same effect. From the clinical record it appears that even a larger amount of plasma (approximately $250 \mathrm{ml}$. from $500 \mathrm{ml}$. of blood) was ineffective although the interval between the end of the transfusion and the subsequent prothrombin determination (approximately six hours) was too long to warrant a definitive conclusion. However, that no significant improvement in clotting was evident six hours after the transfusion serves to differentiate this case from Owren's subject in whom the clot-promoting effect was still detectable several days after a blood transfusion.

Clearly, the administration of normal plasma should have some beneficial effect since mixtures of normal with the pathological plasma exhibit at least the full prothrombic activity of the normal plasma (Table II). The question arises whether more activity is demonstrable than can be accounted for by the normal plasma alone, i.e., whether normal plasma accelerates thrombin evolution from the patient's prothrombin. It would appear that normal plasma was relatively inert in this regard (Table II). This, also, is in sharp contrast to what Owren observed in parahemophilia (1). Some observations, however, indicate that thrombin formation was accelerated under certain circumstances. A 1 to 20 dilution of normal plasma with $\mathrm{BaSO}_{4}$ normal plasma gave a prothrombin 
time of 47 seconds (Table IV). When one part of the pathological plasma was incorporated into the mixture, the prothrombin time was $33{ }^{\circ} \mathrm{sec}-$ onds. This difference, constituting a considerable increase in prothrombic activity, was found also with the patient's prothrombin fraction.

The question whether normal plasma contains an entity deficient in the patient's plasma and capable of correcting its disturbed clotting, seemed sufficiently important to warrant more detailed study. Accordingly, normal plasma was mixed in various dilutions with the pathological plasma, and the prothrombin times of the mixtures were

TABLE VII

Thrombin coolution in various combinations of pathological plasma with normal plasma or serum

\begin{tabular}{|c|c|c|c|c|c|}
\hline \multicolumn{5}{|c|}{ Plasma mixture (parts) } & \multirow[b]{2}{*}{$\begin{array}{c}\text { Proth. } \\
\text { time } \\
\text { (sec.) }\end{array}$} \\
\hline $\begin{array}{c}\text { Norm. } \\
\text { plas. }\end{array}$ & $\begin{array}{l}\text { Pt.'s } \\
\text { plas. }\end{array}$ & $\underset{\text { ser.* }}{\text { Norm. }}$ & $\begin{array}{c}\text { Norm. } \\
\text { BaSO: } \\
\text { plas. }\end{array}$ & $\begin{array}{c}\text { Norm. } \\
\text { partialit } \\
\text { BaSO، } \\
\text { plas. }\end{array}$ & \\
\hline$\frac{1}{二}$ & $\underline{-}$ & $\begin{array}{l}z \\
z\end{array}$ & $\overline{1}$ & $\frac{7}{1}$ & $\begin{array}{r}17 \\
74 \\
>360 \\
70\end{array}$ \\
\hline $\begin{array}{l}1 \\
1 \\
1 \\
-\end{array}$ & $\frac{-}{1}$ & 二 & $\frac{1}{1}$ & $\underline{-}$ & $\begin{array}{l}17 \\
16 \\
17 \\
93\end{array}$ \\
\hline $\begin{array}{l}1 \\
1 \\
1 \\
\end{array}$ & $\begin{array}{r}- \\
4 \\
4\end{array}$ & $\frac{-}{1}$ & $\underline{4}$ & $\overline{4}$ & $\begin{array}{l}22 \\
20 \\
21 \\
17\end{array}$ \\
\hline $\begin{array}{l}1 \\
1 \\
1 \\
-\end{array}$ & $\begin{array}{c}- \\
9 \\
9\end{array}$ & $\frac{-}{1}$ & $\frac{9}{二}$ & $\underline{-}$ & $\begin{array}{l}28 \\
27 \\
25 \\
20\end{array}$ \\
\hline $\begin{array}{l}1 \\
1 \\
1 \\
-\end{array}$ & $\begin{array}{l}-\overline{1} \\
19 \\
19\end{array}$ & $\bar{z}$ & $\frac{19}{=}$ & $\frac{\overline{19}}{-}$ & $\begin{array}{l}39 \\
33 \\
31 \\
25\end{array}$ \\
\hline $\begin{array}{l}1 \\
1 \\
1 \\
-\end{array}$ & $\begin{array}{l}-\overline{2} \\
29 \\
29\end{array}$ & $\frac{二}{1}$ & $\begin{array}{l}29 \\
=\end{array}$ & $\begin{array}{l}\overline{29} \\
-\end{array}$ & $\begin{array}{l}54 \\
40 \\
34 \\
30\end{array}$ \\
\hline $\begin{array}{l}1 \\
1 \\
1 \\
-\end{array}$ & $\begin{array}{l}\bar{Z} \\
39 \\
39\end{array}$ & $\frac{二}{1}$ & $\begin{array}{l}39 \\
=\end{array}$ & $\begin{array}{l}\overline{39} \\
-\end{array}$ & $\begin{array}{l}90 \\
43 \\
36 \\
30\end{array}$ \\
\hline$\overline{-}$ & $\begin{array}{l}1 \\
1\end{array}$ & $=$ & $\begin{array}{r}9 \\
19\end{array}$ & $=$ & $\begin{array}{l}144 \\
270\end{array}$ \\
\hline
\end{tabular}

* Normal non-oxalated serum, devoid of prothrombin, 24 hours old.

† Normal plasma adsorbed with $15 \mathrm{mgm}$. BaSO, per $\mathrm{ml}$. for approximately 10 minutes at $4-5^{\circ} \mathrm{C}$. compared with those of normal plasma similarly diluted with prothrombin-free $\mathrm{BaSO}_{4}$ normal plasma (Table VII). In mixtures containing less than $10 \%$ normal plasma, shorter prothrombin times were observed on normal-pathological plasma mixtures than on the normal- $\mathrm{BaSO}_{4}$ normal plasma counterparts (31 seconds vs. 39 ; 34 vs. 54 ; 36 vs. 90). It should be emphasized that these differences, repeatedly observed, are definitely outside the experimental error of the method.

It was conceivable that the faster thrombin evolution in the normal-pathological mixtures may have been due to the additive effect of the small yet significant prothrombic activity of the abnormal plasma with its prothrombin time of 74 seconds in contrast to that of the $\mathrm{BaSO}_{4}$ normal plasma ( $>360$ seconds). Attempts were therefore made to obtain (for the purpose of a diluent) a $\mathrm{BaSO}_{4}$ normal plasma with a prothrombin time more comparable to that of the pathological plasma. After considerable trial and error, this was accomplished by adsorbing normal plasma with 15 mgm. $\mathrm{BaSO}_{4}$ (C. P.-Baker) at $4-5^{\circ} \mathrm{C}$ for approximately ten minutes. The adsorbed plasma had a prothrombin time of 70 seconds. The prothrombin times of normal-pathological plasma mixtures were also shorter than those of normal plasma similarly diluted with this hypoprothrombinemic plasma (Table VII). Here, too, the differences were evident only at high dilutions, i.e., in mixtures with prothrombin times exceeding 30 seconds.

Additional experiments were performed : 1 part of normal plasma was mixed with 1 part of pathological plasma. The ensuing mixture was then diluted with various amounts of prothrombin-free $\mathrm{BaSO}_{4}$ normal plasma, and the prothrombin times were compared with those simultaneously obtained on normal plasma diluted with the $\mathrm{BaSO}_{4}$ normal plasma. In this way, the same diluent was provided to both the normal plasma and the normalpathological combination. Again, prothrombin conversion seemed faster in mixtures containing both normal and pathological plasma (Figure 5), particularly in the range where the prothrombin time exceeded 28 seconds. Mixtures of pathological plasma alone with the $\mathrm{BaSO}_{4}$ normal plasma gave markedly elevated prothrombin times, which became progressively greater as dilution with the $\mathrm{BaSO}_{4}$ normal plasma was increased. 


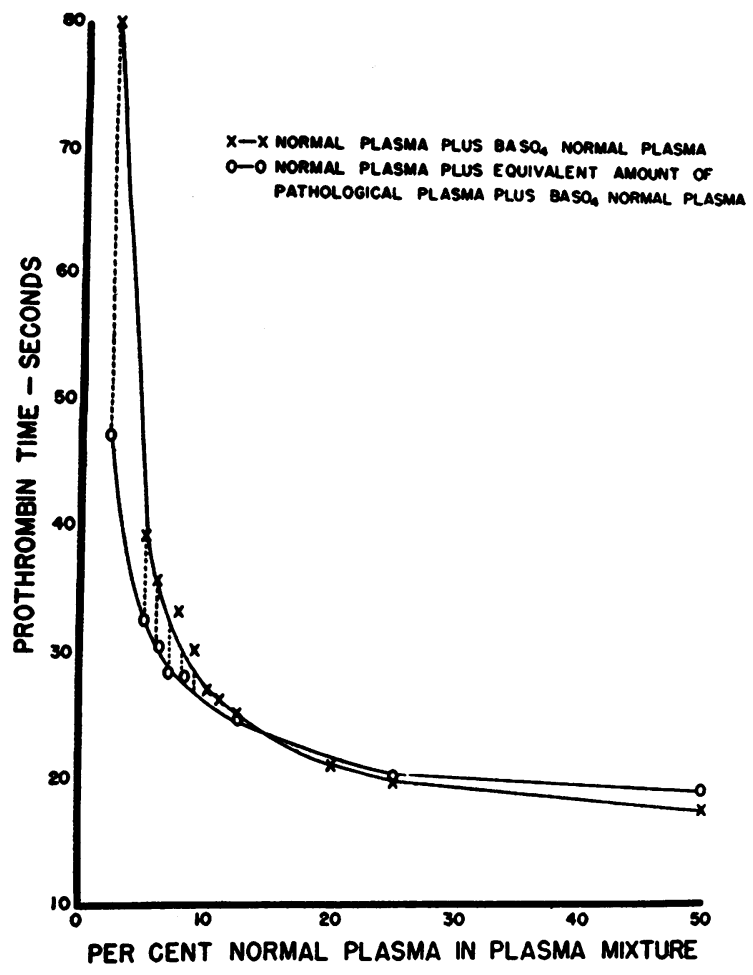

Fig. 5. Prothrombin Times of Mixtures of Patient's Plasma, Normal Plasma, and BaSO, Normal Plasma

Curve with crosses represents normal plasma diluted in $\mathrm{BaSO}_{4}$ normal plasma. Ten\% normal plasma in this mixture signifies 1 part normal plus 9 parts $\mathrm{BaSO}_{4}$ normal; $20 \%, 1$ normal plus $4 \mathrm{BaSO}_{4}$ normal ; .. . etc.

Curve with circles represents observations on normal plus pathological plasma, diluted in $\mathrm{BaSO}_{4}$ normal plasma. Ten\% normal plasma in this mixture signifies 1 part normal, 1 part pathological and 8 parts $\mathrm{BaSO}$, normal plasma ; $20 \%$ represents 1 part normal, 1 part pathological and 3 parts $\mathrm{BaSO}_{4}$ normal, ... etc. Fifty\% represents 1 normal plasma plus 1 pathological plasma.

It might still be argued, nevertheless, that the conditions of the foregoing experiments were not strictly comparable since the pathological plasma contained normal amounts of prothrombin whereas the $\mathrm{BaSO}_{4}$ plasma contained little or none. $\mathrm{Ob}$ viously, this objection could be met only by having available pure prothrombin which could be incorporated into the various plasma mixtures in order to attain comparable prothrombin concentrations.

There can be little doubt, however, that to a certain extent normal plasma can truly rectify the retarded prothrombin conversion of the abnormal plasma. It is, however, far less effective than se- rum (Table VII). Furthermore, the clot-promoting effect of serum, and also of spca preparations, was observable in all ranges of prothrombin time, whereas the nomal plasma seemed effective only in mixtures with prothrombin times in excess of approximately 30 seconds. The explanation of this is obscure. Either the correcting factor in normal plasma is present in critical amounts, insufficient to handle substantial amounts of the additional prothrombin provided by the patient's plasma, or a certain interval (about 30 seconds) is required after the addition of thromboplastin and calcium for the corrective effect of normal plasma to supervene. Certainly the prothrombin method is sufficiently sensitive to have permitted detection of clot-promoting effect also in ranges where the prothrombin times of mixtures were between 20 and 30 seconds. Thus, in the presence of an amount of normal plasma which would give a prothrombin time of less than 30 seconds, the corrective effect of the factor in normal plasma may not be evident if 30 seconds or more is required for its conversion to the component active in correction of the clotting defect.

Regardless of whether this interpretation is correct, the clot-promoting effect of normal plasma provides strong evidence against the hypothesis that the patient's prothrombin was inherently defective. It is more reasonable to conclude that the abnormality lay in deficiency of a coagulation factor present in normal plasma, but absent in $\mathrm{BaSO}_{4}$ plasma.

Clot-promoting effect of dicumarol plasma: Consistent with this conclusion is the observation that hypoprothrombinemic dicumarol plasma also

TABLE VIII

Prothrombic activity of patient's plasma mixed with dicumarol plasma

\begin{tabular}{c|c|c|c}
\hline \multicolumn{2}{c|}{ Plasma mixture (parts) } & $\begin{array}{c}\text { Dicum. } \\
\text { BaSO; } \\
\text { plas. }\end{array}$ & $\begin{array}{c}\text { Proth. time } \\
\text { (sec.) }\end{array}$ \\
\hline Pt.'s plas. & Dicum.* plas. & - & 72 \\
\hline 1 & - & - & 37 \\
\hline 1 & 1 & - & 27 \\
1 & 1 & 1 & 41 \\
\hline
\end{tabular}

* Plasma from subject with myocardial infarct under treatment with dicumarol for prevention of thromboembolic disease. Plasma prothrombic activity $-8 \%$ of normal (one-stage). 
could induce thrombin evolution in the patient's plasma (Table VIII). This finding, furthermore, reflects a striking difference between dicumarol plasma and normal plasma deprothrombinated by $\mathrm{BaSO}_{4}$. Moreover, $\mathrm{BaSO}_{4}$ adsorption of the dicumarol plasma decreases its effect. This lends further support to the concept that the clotting factor present in normal plasma and deficient in the patient is adsorbable by $\mathrm{BaSO}_{4}$.

\section{DISCUSSION}

Recent recognition of the importance of nonprothrombin factors in the conversion of prothrombin has permitted more precise delineation of the coagulation defect in certain patients who formerly would have been erroneously grouped in one category, namely, hypoprothrombinemia. Exhaustive study of these rare cases has led, at least in one instance (1), to the discovery of hitherto unknown clotting components.

The observations contained in this report indicate the existence of another prothrombin-conversion factor besides those already reported. Deficiency in this entity (or its deranged function) results in early retardation of thrombin evolution, a defect which is associated with hemorrhagic phenomena despite essentially normal concentrations of prothrombin, Ac-globulin, L. F., and Factor V.

The existence of another prothrombin-conversion plasma component was postulated by Quick on the basis of observations on two brothers with abnormal bleeding and elevated prothrombin times (19). This moiety, originally termed "prothrombin A," is not reduced by dicumarol in contrast to "prothrombin B," which is probably identical with the purified prothrombin of Seegers, Loomis and Vandenbelt (20). Prothrombin A is said to be adsorbed by alumina and calcium phosphate together with Prothrombin $\mathrm{B}$, in contradistinction to L. F. (19). The subject has been further complicated by the most recent change in terminology by Quick and Stefanini who now consider the total "prothrombin complex" to comprise three components : prothrombin "A," prothrombin "pre-A" and L. F. (18).

Alexander and associates, also, have presented evidence of a prothrombin conversion factor in plasma, distinct from L. F. or Ac-globulin. This entity is probably the inert precursor of spca to which it becomes converted during coagulation $(14,8)$. Like prothrombin, it is adsorbed by $\mathrm{BaSO}_{4}$, and thus is probably identical with Quick's prothrombin A (earlier terminology) and perhaps with Milstone's prothrombokinase, which also is removed by $\mathrm{BaSO}_{4}$ (21). Additional evidence for this factor was obtained by Landwehr and associates on a subject with congenital hypoprothrombinemia (22). When normal plasma was diluted with the prothrombinopenic plasma, the ensuing mixture exhibited considerably faster prothrombin conversion than a mixture of normal plasma with normal plasma deprothrombinated by $\mathrm{BaSO}_{4}$ Furthermore, treatment of the prothrombinopenic plasma with this adsorbing agent obviated the accelerating effect, yielding a plasma indistinguishable from normal $\mathrm{BaSO}_{4}$ plasma. Evidently, this patient's plasma contained a prothrombin-conversion substance adsorbable by $\mathrm{BaSO}_{4}$ and not present in $\mathrm{BaSO}_{4}$ normal plasma.

From the data of the present report it is concluded that our patient's clotting disturbance consisted in deficiency of this entity, the precursor of spca. We have seen that the pathological serum contained little spca after coagulation had run its course, and that normal serum or spca fractions rectified the retarded prothrombin activation. Furthermore, removal of spca rendered the serum inert.

Also in harmony with this interpretation are some of the other observations. Whereas normal or dicumarol plasma can partially correct the clotting defect, adsorption of the plasmas with $\mathrm{BaSO}_{4}$ renders them relatively inert. This indicates that $\mathrm{BaSO}_{4}$ removes the accessory factor in question. It also explains why the patient's plasma, assumed to be deficient in this entity, acted almost the same as $\mathrm{BaSO}_{4}$ normal plasma as a diluent for normal plasma in the one-stage test. Furthermore, prothrombin preparations obtained from the abnormal plasma would be expected, as was found, to show the same clotting defect when mixed with $\mathrm{BaSO}_{4}$ normal plasma.

Certain deductions may be drawn regarding the role of this clotting factor in prothrombin conversion. By the two-stage method, the rate of thrombin evolution as well as the final yield of thrombin from the patient's prothrombin appeared 
normal. Also, prothrombin consumption during spontaneous coagulation was unimpaired. Since under these conditions the prothrombin conversion process can be accurately followed except during the first few minutes after the addition or appearance of thromboplastin, it may be justifiably concluded that the clotting derangement lay in this phase of prothrombin activation, indeed, in the very interval represented by the elevated one-stage prothrombin time. It thus appears that the clotting factor, deficient in the pathological plasma, functions somehow in the early activation of prothrombin by thromboplastin plus calcium. Its similarity, in this regard also, to Milstone's prothrombokinase is striking (21).

The discrepancy in "prothrombin" values obtained on this patient by the one- and two-stage procedures raises questions regarding the validity of these methods, and their clinical diagnostic value. Obviously, the clotting disturbance would have escaped detection had the two-stage system been used exclusively. On the other hand, it is equally clear that the one-stage test, even the modification using $\mathrm{BaSO}_{4}$ normal plasma as a diluent to assure adequate L. F., may fail to measure prothrombin specifically, since it is now apparent that $\mathrm{BaSO}_{4}$ removes an important accessory substance. As has been emphasized elsewhere $(9,22,23)$, unless due consideration is given to all the prothrombin-conversion factors as well as to the concentrations of fibrinogen, antithrombin and anticoagulants, translation of an observed prothrombin time into a specific prothrombin value may be fraught with serious error. Nevertheless, this case demonstrates the distinct value of the one-stage method in disclosing certain clotting abnormalities centered around the conversion of prothrombin to thrombin.

The clot-promoting effect of serum and purified spca is of practical as well as theoretical interest. To reduce the prothrombin time from 70 to $22 \mathrm{sec}-$ onds is tantamount to increasing plasma prothrombic activity from about $3 \%$ to $25 \%$ of normal, a level which is consistent with effective hemostasis if other hemostatic mechanisms are normal (9). It has been shown that serum as well as purified spca can promote the coagulation of normal blood, hemophilic blood, thrombocytopenic blood, heparinized blood and blood exposed to siliconized sur- faces (8). The therapeutic possibilities of serum were explored with good results by Crockett and colleagues (24) in a case of "idiopathic hypoprothrombinemia." It is noteworthy that in their subject, plasma seemed equally effective, the beneficial results of each lasting for 24 hours or more in contrast to the relatively shortlived effect of serum in our case. These authors attributed the clot-promoting property of serum to Ac-globulin, probably not being aware of the fact that one to two hour old human serum is practically devoid of Acglobulin activity $(15,8)$.

The normal prothrombin consumption in our case is worthy of additional comment. Since poor prothrombin utilization characteristically occurs in hemophilia, thrombocytopenia, thrombasthenia and certain and other hemorrhagic states associated with defective coagulation, the prothrombin consumption test promises to become important in distinguishing hemorrhagic conditions, related to clotting abnormalities, from other forms of pathological bleeding. That our patient's defect was associated with normal prothrombin consumption is, therefore, particularly noteworthy. Furthermore, it renders untenable our earlier concept that spca elaboration is related to the amount and/or velocity of prothrombin conversion $(6,7)$. Also, it signifies the importance in normal hemostasis of the kinetics of thrombin elaboration rather than the overall amount of prothrombin converted.

The literature fails to reveal cases which completely simulate that presented in this report. Quick (19) described two brothers with elevated prothrombin times which he attributed to deficiency of "prothrombin A" (earlier terminology). It is of interest that these subjects also showed good prothrombin consumption. Unfortunately, they were not exhaustively studied by simultaneous one- and two-stage prothrombin determinations as well as by measurements of plasma Acglobulin and serum spca. The condition was called "pseudohypoprothrombinemia," a term which we consider more suitably applicable to a group of disorders including Ac-globulin deficiency (parahemophilia) and the derangement represented by our case. Since in our subject the condition was evident at birth, it is most probably congenital in origin. 


\section{SUMMARY}

A clinical and laboratory study is presented of a four year old girl with a hemorrhagic diathesis present since birth. An elevated one-stage prothrombin time was the cardinal abnormality. Plasma prothrombin was qualitatively and quantitatively normal by the two-stage procedure, as were also plasma Ac-globulin and Labile Factor. Several other features distinguished this case from parahemophilia (Factor V deficiency). Also excluded were anticoagulants as well as possible abnormalities in the antithrombin mechanism or in the thrombin-fibrinogen interaction.

Prothrombin conversion was retarded in the early phase of prothrombin activation, but prothrombin consumption was normal, being virtually complete within 30 to 60 minutes after the blood was shed. The coagulation defect appeared to consist of deficiency of another prothrombin-conversion accessory factor which is present in normal or dicumarol plasma in limited amount, and which is adsorbable by $\mathrm{BaSO}_{4}$. Since spca was decreased in the patient's serum, and since normal serum or purified spca rectified the clotting abnormality, it is concluded that the entity deficient in the pathological plasma is the precursor of spca. The disorder may be considered a form of pseudohypoprothrombinemia, alongside Ac-globulin deficiency (parahemophilia), and constitutes a hitherto unknown pathologic state added to the many already recognized hemorrhagic conditions related to clotting abnormalities of congenital origin.

\section{REFERENCES}

1. Owren, P. A., Parahaemophilia: haemorrhagic diathesis due to absence of a previously unknown clotting factor. Lancet, 1947, 1, 446.

2. Owren, P. A., The coagulation of blood: investigations on a new clotting factor. Acta med. Scandinav., 1947, Suppl. 194, 1.

3. Sykes, E. M., Jr., Seegers, W. H., and Ware, A. G., Effect of acute liver damage on ac-globulin activity of plasma. Proc. Soc. Exper. Biol. \& Med., 1948, 67, 506.

4. Alexander, B., and Goldstein, R., Coagulation defect in hepatic disorders: deficiency of prothrombin-conversion accessory substances. J. Clin. Invest., 1950, 29, 795.

5. de Vries, A., Alexander, B., and Goldstein, R., A factor in serum which accelerates the conversion of prothrombin to thrombin. I. Its determination and some physiologic and biochemical properties. Blood, 1949, 4, 247.

6. Alexander, B., de Vries, A., and Goldstein, R., A factor in serum which accelerates the conversion of prothrombin to thrombin. II. Its evolution with special reference to the influence of conditions which affect blood coagulation. Blood, 1949, 4, 739.

7. Alexander, B., de Vries, A., Goldstein, R., and Landwehr, G., A prothrombin conversion accelerator in serum. Science, 1949, 109, 545.

8. Alexander, B., Goldstein, R., and Landwehr, G., The prothrombin conversion accelerator of serum (spca) : its partial purification and properties compared with serum Ac-globulin. J. Clin. Invest., 1950, 29, 881.

9. Alexander, B., de Vries, A., and Goldstein, R., Prothrombin: a critique of methods for its determination and their clinical significance. New England J. Med., 1949, 240, 403.

10. Warner, E. D., Brinkhouse, K. M., and Smith, H. P., A quantitative study on blood clotting: prothrombin fluctuations under experimental conditions. Am. J. Physiol., 1935-36, 114, 667.

11. Ware, A. G., and Seegers, W. H., Two-stage procedure for the quantitative determination of prothrombin concentration. Am. J. Clin. Path., 1949, 19, 471.

12. Quick, A. J., and Stefanini, M., The concentration of the labile factor of the prothrombin complex in human, dog and rabbit blood; its significance in the determination of prothrombin activity. J. Lab. \& Clin. Med., 1948, 33, 819.

13. Alexander, B., Landwehr, G., and Goldstein, R., Labile factor of prothrombin conversion: its consumption in normal and abnormal blood coagulation. Federation Proc., 1950, 9, 4.

14. Alexander, B., and Landwehr, G., Evolution of a prothrombin conversion accelerator in stored human plasma and prothrombin fractions. Am. J. Physiol., 1949, 159, 322.

15. Murphy, R. C., and Seegers, W. H., Concentration of prothrombin and Ac-globulin in various species. Am. J. Physiol., 1948, 154, 134.

16. Alexander, B., and de Vries, A., Human prothrombin: quantitative studies on the labile factor and the restorative effects of normal, hypofibrinogenemic and hemophilic plasma on the prothrombin of stored plasma. J. Clin. Invest., 1949, 28, 24.

17. Stefanini, M., and Quick, A. J., Effect of various adsorbants on the components of the prothrombin complex. Federation Proc., 1949, 8, 255.

18. Quick, A. J., and Stefanini, M., The state of component A (prothrombin) in human blood; evidence that it is partly free and partly in an inactive or precursor form. J. Lab. \& Clin. Med., 1949, 34, 1203.

19. Quick, A. J., Congenital hypoprothrombinaemia and pseudo-hypoprothrombinaemia. Lancet, 1947, $2,379$. 
20. Seegers, W. H., Loomis, E. G., and Vandenbelt, J. M., Preparation of prothrombin products: isolation of prothrombin and its properties. Arch. Biochem., $1945,6,85$.

21. Milstone, J. H., Three-stage analysis of blood coagulation. J. Gen. Physiol., 1948, 31, 301.

22. Landwehr, G., Lang, H., and Alexander, B., Congenital hypoprothrombinemia: a case study with particular reference to the role of non-prothrombin factors in the conversion of prothrombin. Am. J. Med., 1950, 8, 255.

23. Alexander, B., and Landwehr, G., Prothrombin consumption, serum prothrombic activity and prothrombin conversion accelerator in hemophilia and thrombocytopenia. J. Clin. Invest., 1949, 28, 1511.

24. Crockett, C. L., Jr., Shotton, D., Craddock, C. G., Jr., and Leavell, B. S., Hypoprothrombinemia. Studies of a case of the idiopathic type and the effect of serum administration. Blood, 1949, 4, 1298. 